\title{
Application of Reliability-Based Robustness Assessment of Steel Moment Resisting Frame Structures under Post-Mainshock Cascading Events
}

\author{
Filipe L. A. Ribeiro'; André R. Barbosa, M.ASCE${ }^{2}$; and Luís C. Neves ${ }^{3}$
}

\begin{abstract}
This paper proposes a reliability-based framework for quantifying structural robustness considering the occurrence of a major earthquake (mainshock) and subsequent cascading hazard events, such as aftershocks that are triggered by the mainshock. These events can significantly increase the probability of failure of buildings, especially for structures that are damaged during the mainshock. The application of the proposed framework is exemplified through three numerical case studies. The case studies correspond to three SAC steel moment frame buildings of three, nine, and 20 stories, which were designed to pre-Northridge codes and standards. Two-dimensional nonlinear finiteelement models of the buildings are developed with the Open System for Earthquake Engineering Simulation framework (OpenSees), using a finite length plastic hinge beam model and a bilinear constitutive law with deterioration, and are subjected to multiple mainshock-aftershock seismic sequences. For the three buildings analyzed herein, it is shown that the structural reliability under a single seismic event can be significantly different from that under a sequence of seismic events. The reliability based robustness indicator shows that the structural robustness is influenced by the extent to which a structure can distribute damage. DOI: 10.1061/(ASCE)ST.1943-541X.0000939. (C) 2014 American Society of Civil Engineers.
\end{abstract}

Author keywords: Aftershock; Nonlinear dynamic analysis; Robustness; Seismic sequences; Structural Safety and Reliability.

\section{Introduction}

Structures in earthquake prone regions are susceptible to being damaged as a result of intense ground motion shaking. Traditionally, the design and analysis of building structures only consider one single earthquake event, also known as mainshock. However, in reality, structures can be subjected to cascading events, defined as events likely to be triggered by a major earthquake, such as aftershocks, fires, explosions, or tsunamis. The focus of this work is placed on sequences of ground motions that include the mainshock and aftershocks. Structural damage is typically observed in large intensity mainshocks. Because the typical time interval between mainshocks and aftershocks is small, structural repair or retrofit is not possible; thus, the mainshock-damaged structures are more susceptible to failure when an aftershock occurs. The term "failure," as used herein, is synonymous with exceeding a defined limit state that may render structures unfit for use (Newmark and Rosenbleuth 1971).

${ }^{1}$ Ph.D. Student, Dept. of Civil Engineering, Faculdade de Ciências e Tecnologia, Universidade Nova de Lisboa, Quinta da Torre, 2829-516 Caparica, Portugal; and Visiting Ph.D. Student, School of Civil and Construction Engineering, Oregon State Univ., 101 Kearney Hall, Corvallis, OR 97331-3212. E-mail: f.ribeiro@fct.unl.pt

${ }^{2}$ Assistant Professor, School of Civil and Construction Engineering, Oregon State Univ., 101 Kearney Hall, Corvallis, OR 97331-3212 (corresponding author). E-mail: andre.barbosa@oregonstate.edu

${ }^{3}$ Lecturer, Nottingham Transportation Engineering Center, Faculty of Engineering, Univ. of Nottingham, Nottingham NG7 2RD, U.K.; formerly, Dept. of Civil Engineering, Faculdade de Ciências e Tecnologia, Universidade Nova de Lisboa, Quinta da Torre, 2829-516 Caparica, Portugal. E-mail: luis.neves@nottingham.ac.uk

Note. This manuscript was submitted on December 22, 2012; approved on September 6, 2013; published online on March 10, 2014. Discussion period open until August 10, 2014; separate discussions must be submitted for individual papers. This paper is part of the Journal of Structural Engineering, (C) ASCE, ISSN 0733-9445/A4014008(12)/\$25.00.
In this paper, a measure of structural robustness is used to characterize the effect of aftershocks on the seismic safety of structures. With respect to aftershocks triggered by mainshocks, a structure is said to be more or less robust depending on its capacity to sustain post-mainshock damage without reaching failure. Three primary approaches for quantifying structural robustness have been proposed in the literature. In the first approach, measures of structural robustness are derived from probabilistic risk assessments (Baker et al. 2008). Baker et al. (2008) defined a measure for quantifying structural robustness as a function of direct and indirect risk. Although this approach is very powerful, the complexity and subjectiveness in the quantification of the direct and indirect risk in large structural systems hinders the application of this approach. In the second approach, measures of structural robustness are quantified in terms of ratios of structural properties (e.g., damage, energy, or stiffness) between undamaged and damaged structures (Starossek 2006; Cavaco et al. 2013). Although these measures are useful in engineering practice, they fail to explicitly describe failures. Finally, in the last approach, measures of structural robustness are defined as a function of the probabilities of failure of the intact and damaged structure. Examples of such measures are the indexes presented by Frangopol and Curley (1987) and Lind (1995). As discussed in the work of Starossek and Haberland (2008), both of these measures evaluate structural redundancy rather than robustness. However, for buildings, redundancy is provided by the existence of alternative load paths, which are the primary mechanisms providing robustness, rendering these indicators adequate indirect measures structural robustness. Robustness assessment of structures for cascading hazards is currently lacking in the literature.

There are two primary challenges in modeling the effects of aftershock events on structures for computing structural robustness. The first challenge is related to the accurate modeling of expected mainshock-aftershock seismic sequences. This has been discussed extensively by Ruiz-García (2012), Fragiacomo et al. (2004), 
Lee and Foutch (2004), Li and Ellingwood (2007), Luco et al. (2004, 2011), and Ryu et al. (2011). Luco et al. (2011) and Ryu et al. (2011) performed mainshock-aftershock incremental dynamic analyses (IDAs) (Vamvatsikos and Cornell 2002) on single-degree-of-freedom models subjected to artificial sequences of mainshock-aftershock "back-to-back" structural analyses. The second challenge is related to accurate modeling of the effects of damage introduced by the mainshock on structural performance. To this effect, state of the art modeling for the estimation of structural performance/damage can be found in ATC-72 [Pacific Earthquake Engineering Research Center/Applied Techonology Council (PEER/ATC) 2010]. In the ATC-72 report, emphasis is placed on phenomenological models that capture the primary effects of strength and stiffness deterioration.

In this study, a probabilistic framework is developed for the assessment of structural robustness under mainshock triggered aftershocks. Emphasis is placed on the evaluation of the structural robustness as a function of the probability of failure (or the reliability index) under different damage scenarios. In the probabilistic methodology, nonlinear dynamic time history analyses of structural computational models of buildings are used to estimate the recorded structural damage attributable to multiple mainshockaftershock sequences. Mainshock and aftershock incremental dynamic analyses are conducted following the approach proposed by Ryu et al. (2011), in which artificial mainshock-aftershock sequences are used in the back-to-back nonlinear dynamic timehistory analyses. This approach is applied to multi-degree-offreedom (MDOF) structural models of the three, nine, and 20-story steel moment resisting frames (SMRFs) of the SAC steel project (FEMA 2000a). The analytical building models are developed using the Open System for Earthquake Engineering Simulation (OpenSees) and validated by using the numerical data available in the literature (FEMA 2000a; Luco 2002). Important aspects of beam strength and stiffness degradation as damage progresses during the analysis are also included in the model. To quantify the damage attributable to the mainshock and aftershock, the buildings are first subjected to a mainshock IDA, and for each level of the intensity of the mainshock, the mainshock-damaged structure is subjected to IDA attributable to the aftershocks.

\section{Framework}

The framework proposed for the assessment of the structural robustness of buildings is schematically presented in Fig. 1. The first step of the analysis corresponds to the definition of the engineering measures that define failure and the thresholds used to define the performance or limit states. The following step of the analysis corresponds to the definition of the mainshock hazard. This depends on the location of the building and the foundation soil. Extensive data exists on the seismic hazard of locations in Europe, North America, and Japan (Petersen et al. 2008). From this, the mean annual rate of exceeding a ground motion intensity measure can be defined; consequently, a probabilistic distribution of the mainshock intensity measure can be obtained. The ground motion intensity measure most often used is the 5\% damped linear elastic spectral acceleration at the fundamental period of the structure $T_{1}$, which is denoted as $S_{a}\left(T_{1}\right)$ (Baker 2007). Herein, the notation $S$ will be used to refer to spectral acceleration at the fundamental period of the structure.

Based on the definition of the hazard, a set of mainshock ground accelerograms can be defined (Step 3.1 in Fig. 1), considering either real or artificial accelerograms (Bommer and Acevedo 2004). Considering the uncertainty in the characteristics of the mainshock, several different accelerograms should be used; methods for estimating the structural response attributable to the mainshock are discussed by Baker (2007), for example. When probabilistic simulation is employed, a set of mainshocks is used following the distribution of the spectral acceleration. In Step 3.2 in Fig. 1, finite-element models are defined, leading to sufficient accuracy to characterize the nonlinear response to collapse, providing reliable estimates of the residual displacements and loss in stiffness and strength. Details on an example of models that can be employed to account for the strength and stiffness deterioration are described in the following section. In Step 3.3 in Fig. 1, the damage caused by the mainshock is evaluated for each of these samples. In the present paper, this is done by using an IDA (Vamvatsikos and Cornell 2002), but other methods can be defined for estimating the damage conditional on the ground motion intensity measure of the mainshock. Based on the results of these analyses, in Step 3.4 , the probability of failure under mainshock alone $\left(p_{f 1}\right)$ can be estimated by using

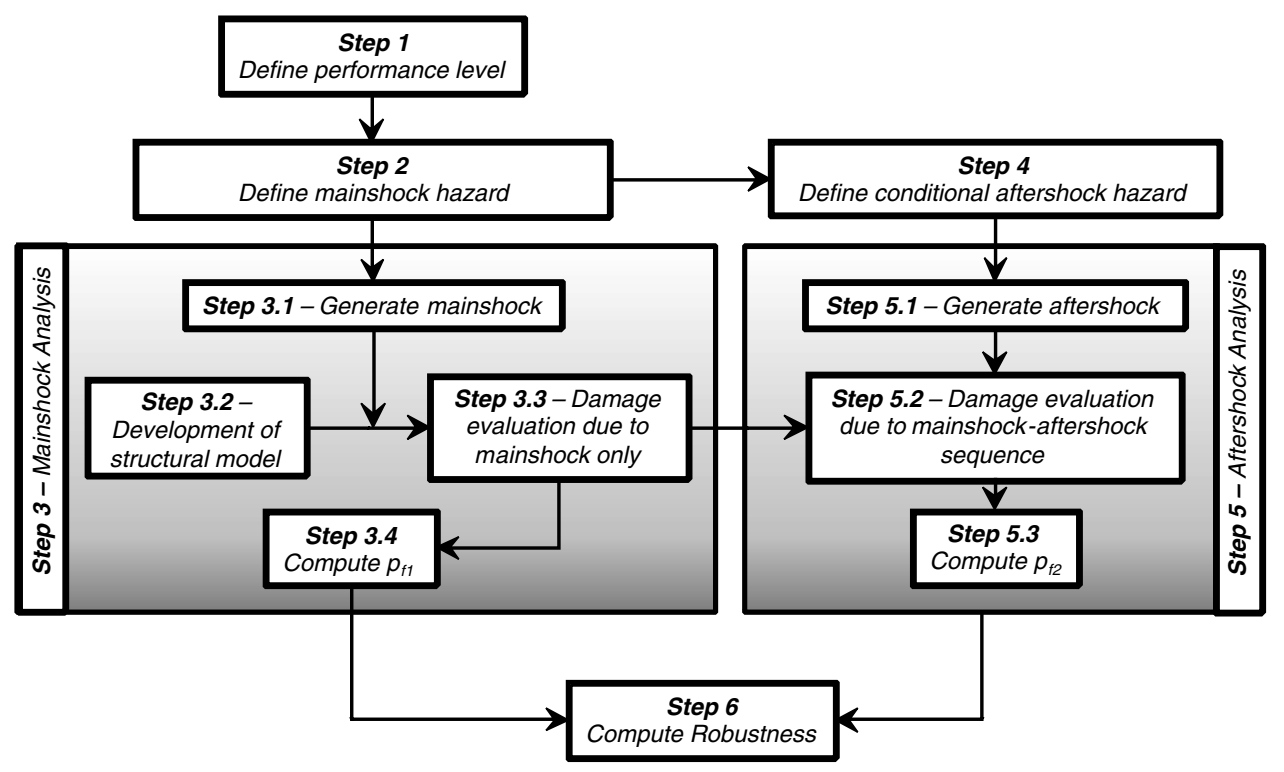

Fig. 1. Flowchart for the robustness assessment of buildings subjected to cascading seismic events 


$$
p_{f 1}=\int_{S^{m}} P\left(F \mid S^{m}=s^{m}\right) d P\left(S^{m}\right)
$$

where $S^{m}=$ ground motion spectral accelerations associated with the mainshock at the fundamental period of the intact structure; $P\left(S^{m}\right)=$ annual probability of occurrence of a spectral acceleration associated with the mainshock; and $P\left(F \mid S^{m}=s^{m}\right)=$ probability of failure $F$ conditional on $S^{m}$. The probabilities of exceedance of a given $S^{m}$ are defined by considering, for example, the data described by Petersen et al. (2008). According to Jayaram and Baker (2008), the spectral accelerations follow lognormal distributions. The term $F$ describes a failure event, which is defined as the exceedance of a limit state. When considering a collapse limit state, for example, FEMA (2000b) reports $5 \%$ as a limiting value interstory drift ratio in buildings. Eq. (1) is applicable for any limit state.

Based on the properties of the mainshock, the conditional aftershock hazard can be defined in Step 4. The occurrence rate and the distribution of aftershocks have strong correlations with the magnitude of the mainshock (Yeo and Cornell 2005). As a consequence, an aftershock hazard should be defined by considering the amplitude, frequency content, and duration of the mainshock. Therefore, the simulation of mainshock-aftershock ought to be performed with real sequences. However, such information in not available for most sites and a general formulation cannot rely on the existence of this data. Thus, artificial mainshock-aftershock sequences are used herein, following Luco et al. (2011), Ryu et al. (2011), and Li et al. (2012). In Step 5.1, a set of aftershock ground accelerations is defined. In Step 5.2, damage resulting from mainshock and aftershock is evaluated, following the tasks described previously for the mainshock alone. The probability of failure attributable to the aftershock, conditional on the occurrence of a mainshock that does not lead to failure, $p_{f 2}$, can be computed by

$$
p_{f 2}=\frac{p_{f 3}-p_{f 1}}{1-p_{f 1}}
$$

where the probability of failure considering both mainshock and aftershock, computed in Step 5.3, is given by

$$
p_{f 3}=\int_{S^{m}} \int_{S^{a}} P\left(F \mid S^{m}=s^{m}, S^{a}=s^{a}\right) d P\left(S^{a} \mid S^{m}=s^{m}\right) d P\left(S^{m}\right)
$$

where $S^{a}=$ ground motion spectral accelerations associated with the aftershock at the fundamental period of the intact structure; $P\left(S^{a} \mid S^{m}=s^{m}\right)=$ conditional probability of occurrence of an aftershock with spectral acceleration $S^{a}$ following a mainshock with spectral acceleration $S^{m}$; and $P\left(F \mid S^{m}=s^{m}, S^{a}=s^{a}\right)=$ probability of failure $F$ conditional on $S^{m}$ and $S^{a}$; $S^{a}$ is also assumed to follow a lognormal distribution.

In Step 6, the robustness assessment is performed based on a comparison of the reliability index $\left[\beta=-\Phi^{-1}\left(p_{f}\right)\right]$ of the undamaged structure $\beta_{\text {intact }}$, which only accounts for the mainshock, with the reliability index of the mainshock-damaged structure $\beta_{\text {damaged }}$ as follows (Frangopol and Curley 1987):

$$
\beta_{R}=\frac{\beta_{\text {intact }}}{\beta_{\text {intact }}-\beta_{\text {damaged }}}
$$

where $\beta_{\text {intact }}=-\Phi^{-1}\left(p_{f 1}\right)$ and $\beta_{\text {damaged }}=-\Phi^{-1}\left(p_{f 2}\right)$.

Herein, the reliability index for the mainshock $\beta_{\text {intact }}$ is computed by considering the spectral acceleration event space divided into 10 intervals for 10 equally likely ground motion records, each denoted as earthquake $E_{j}$ by using a technique known as stratified sampling (Kiureghian 1996). The reliability index for the aftershock $\beta_{\text {damaged }}$ is computed using stratified sampling for the spectral acceleration of the mainshock and considering the conditional probability of failure attributable to aftershock as the probability of exceedance of the minimum aftershock spectral acceleration leading to failure. The probability of failure is computed considering the combination of 10 mainshock and 10 aftershock ground motion records. In this computation, it is assumed that the ground motion spectral acceleration of the mainshock and the aftershock are uncorrelated.

\section{Building Models}

\section{General Description}

The SMRF buildings studied in this work are a subset of the models developed as part of the SAC steel project (FEMA 2000a). The buildings included in this study are three, nine, and 20-story buildings (denoted LA3, LA9, and LA20, respectively), which were designed for Los Angeles by using pre-Northridge codes [International Conference of Building Officials (ICBO) 1994]. In all buildings, external frames were designed to resist the lateral seismic loads and interior frames were designed as gravity frames. As shown in Fig. 2, all buildings have spans of $9.15 \mathrm{~m}$ in both directions. The three-story building presents no basement, whereas the nine and 20-story buildings have one and two basement levels, respectively. The height of the frames is constant and equal to $3.96 \mathrm{~m}$, except for the first levels of the two taller buildings, which each have a height of $5.49 \mathrm{~m}$, as shown in Fig. 2. A detailed description of the buildings is presented in FEMA 355C (2000a) and Luco (2002).

Two-dimensional centerline models of an external frame of each of the three buildings are used for the structural analysis. According to one of the modeling alternatives presented by Luco and Cornell (2000), strong-column weak-beam ductile behavior was assumed for all structures. Brittle mechanisms and connection fracture modes were not considered.

Geometric nonlinearities are accounted for during the analysis by considering a $P-\Delta$ leaning column. A rigid diaphragm is assumed for each floor. Soil-structure interaction is not considered. Masses and loads are applied to beam-column joints. Similar to the definition in FEMA 355C (2000a), Rayleigh damping is assigned to the models. As described by Erduran (2012), a damping ratio of $2 \%$ is assigned to the first mode and a higher mode. Following FEMA 355C (2000a), the higher mode under consideration is the fifth mode for LA20 and a mode with period of $0.2 \mathrm{~s}$ for buildings LA3 and LA9 (a period close to LA3's third modal period and LA9's fifth modal period).

\section{Component Modeling}

The nonlinear behavior of the building was modeled considering a set of four different models for each structure, as described in Table 1. The four models differ in the method used to simulate the beams. For the first two models, a zero-length plastic hinge element is used, considering elasto-plastic behavior with hardening and a bilinear model with deterioration ("Bilin" model in OpenSees). The third and fourth models use the same material models, but consider a finite-length plastic hinge element. In all four cases, the columns are modeled by considering a distributed plasticity model and an elasto-plastic constitutive law with a 3\% hardening rate assigned to each fiber. A moment curvature section analysis shows that this corresponds to a section hardening of approximately $3.0 \%$, consistent with the assumptions used in the modeling for FEMA 355C (2000a). Thus, for the columns, the primary 


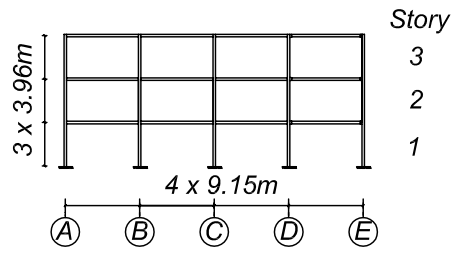

(a)

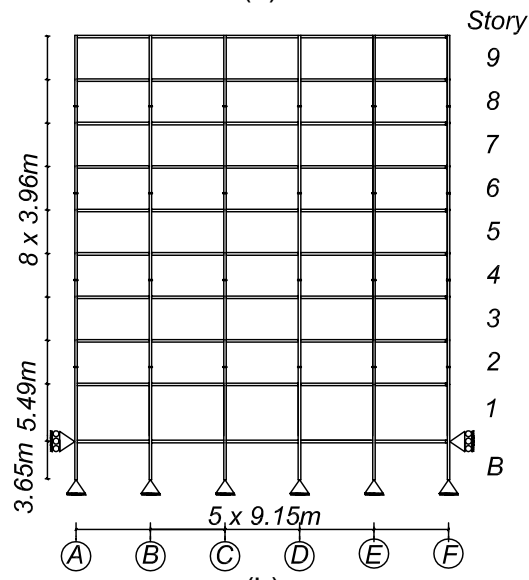

(b)

Fiber-model P-M Interaction

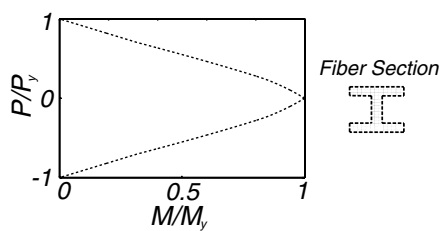

(d)

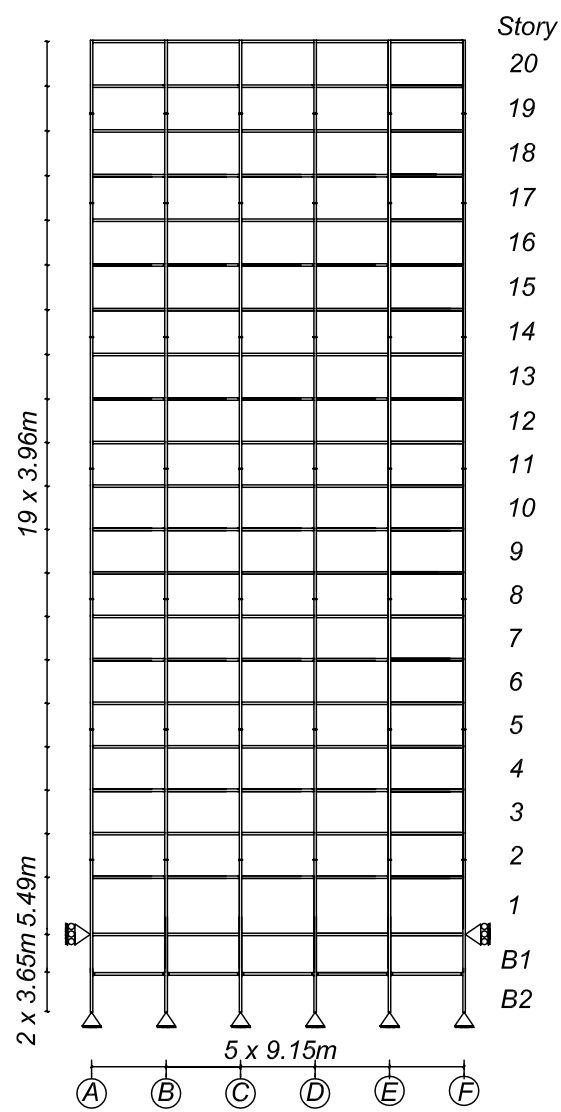

(c)

Fig. 2. (a) LA3 building model; (b) LA9 building model; (c) LA20 building model; (d) P-M interaction curve

Table 1. Description of the Models

\begin{tabular}{lccccc}
\hline & \multicolumn{2}{c}{ Columns } & & \multicolumn{2}{c}{ Beams } \\
\cline { 2 - 3 } Model & Element formulation & Material & & Element formulation & Material \\
\hline FZLH & Force-based fiber & Elasto-plastic & & Zero length & Elasto-plastic with hardening \\
FZLB & section distributed plasticity & with hardening & & (concentrated plasticity) & Bilinear with deterioration (Bilin) \\
FMRH & & & Finite-length plastic & Elasto-plastic with hardening \\
FMRB & & & hinge (modified Radau) & Bilinear with deterioration (Bilin) \\
\hline
\end{tabular}

phenomenon under consideration is the interaction between moment and axial load. This assumption is supported by recent testing (Newell and Uang 2008), in which it is shown that columns such as the ones being modeled do not exhibit deterioration in strength by more than $10 \%$ for $P / P y \leq 0.75$, even at $8 \%$ story drift ratios. For the building under analysis, which was designed by using the strong column, weak beam assumption, only minor deterioration is expected in the stiffness and strength of columns and disregarding these effects will have no significant impact on the results. However, for buildings consisting of slender columns, this assumption may not hold and the effect of deterioration of the strength and stiffness of the columns should be evaluated.

Model idealizations for nonlinear structural analysis of beams range from phenomenological models, such as concentrated plasticity models and finite-element distributed plasticity beamcolumn elements, to complex continuum models based on plane stress or solid finite elements. In the concentrated plasticity models
(Giberson 1969), nonlinear zero-length springs are discretized at both ends of a linear-elastic beam-column element. These elements have been recently proposed as the primary method for estimating seismic demands (Ibarra and Krawinkler 2005; Medina and Krawinkler 2005; Haselton and Deierlein 2007) and are the preferred modeling approach in the recently proposed modeling guidelines in ATC-72 (PEER/ATC 2010). Considering that zero-length models have been widely used to model the seismic performance of buildings, they are used as a reference in this work and the results obtained by using the finite-length plastic hinge elements are compared with them to ascertain their accuracy.

Scott and Fenves (2006) proposed a novel approach for modeling nonlinear behavior of frame structures based on force based finite-length plastic hinge beam-column elements (beams with hinges), which overcomes concerns related to localization phenomena observed in distributed plasticity beam-column elements (Coleman and Spacone 2001). Furthermore, finite-length plastic 
hinge elements can explicitly model plastic hinge length and separate the behavior of the beam in the span from that of beam-column connections. Compared to zero-length springs, finite-length plastic hinge elements allow faster model development as a result of the reduction in the number of nodes and elements.

Steel structures are traditionally modeled considering an elastoplastic behavior with kinematic hardening, accounting for the Bauschinger effect. However, during an earthquake, structural elements are subjected to large inelastic cyclic deformations, which lead to deterioration of both the strength and stiffness properties of components, affecting the overall structural performance under seismic loading.

In the present work, a modified version of the phenomenological model proposed by Ibarra and Krawinkler (2005), applicable to any force deformation relationship, is employed to simulate beam behavior and compared to a bilinear model with kinematic hardening. This model was used by Lignos and Krawinkler (2011) to model the moment-rotation relationship of plastic hinges in steel elements. The model considers strength and stiffness deterioration, defined in terms of element geometry, material properties, and cross-sectional geometry.

The model by Lignos and Krawinkler (2011) defines a momentrotation relationship, and consequently, cannot be directly applied when a finite-length plastic hinge is considered, which requires the use of a moment-curvature relationship. Based on the momentrotation model described previously, it is possible to define the moment-curvature, $M-\chi$, model by scaling the moment-rotation backbone curve and the loading and unloading rules in terms of the length of the plastic hinge, $L_{p}$, resulting in the model presented in Fig. 3. This plastic hinge moment-rotation model is based on the assumption of a double curvature deformation, which leads to an

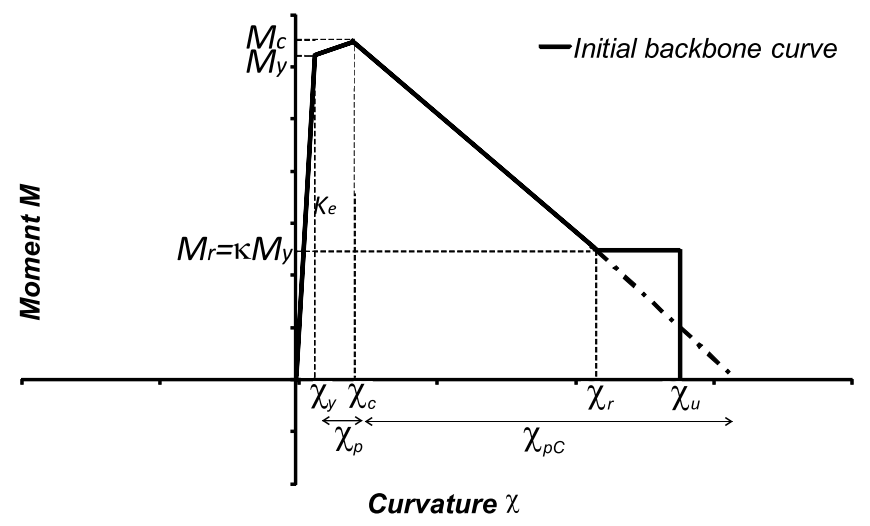

(a)

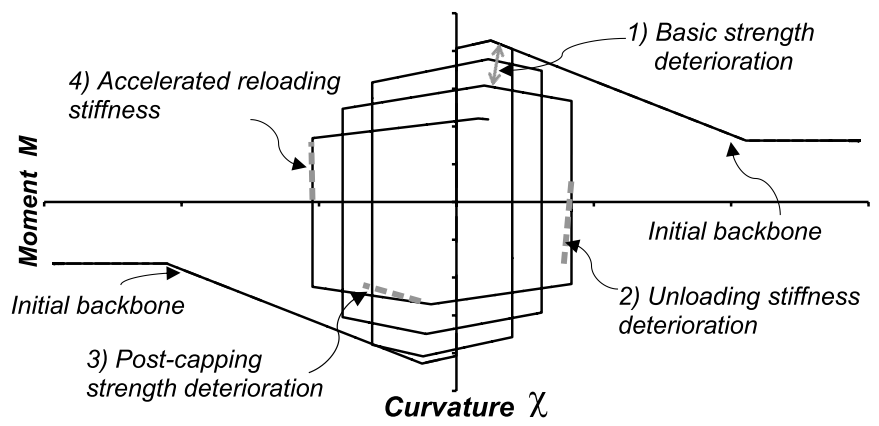

(b)

Fig. 3. Model adapted and modified from Ibarra and Krawinkler (2005): (a) backbone curve; (b) basic modes of cyclic deterioration elastic stiffness of $6 E I / L$. When a finite-length plastic hinge element is used, a plastic hinge length of $L_{p}=L / 6$ should be used to recover the exact solution for the case of a fixed-fixed beam column element (Scott and Ryan 2013). All other model parameters are defined as proposed by Lignos and Krawinkler (2011, 2012). Axial and shear behavior is assumed to be linear elastic. Joint shear deformations (Gupta and Krawinkler 1999) and fracture attributable to low cycle fatigue (Lignos et al. 2011) are not included in this work.

For the building examples under analysis, the axial load expected to develop in beams is very low and the interaction between axial load and bending moment in beams is significantly less relevant than the deterioration of stiffness and strength, which is expected to occur in the beams. For this reason, the interaction between axial load and bending moment is disregarded for the beams. The modeling assumptions made in this work are intended to provide a relatively simple structural model, and at the same time, to accurately simulate the deterioration of the steel members to collapse. Thus, the modeling of some building components is neglected in these models, such as beam-column joints, column base plate connections, and partially restrained connections. The influence of these components in the robustness of steel structures to cascading events is worth studying in future works.

\section{Model Validation}

The four models are compared to those developed by Luco and Cornell (2000), also designated as Model M1 (FEMA 2000a), for the same buildings. The models described by Luco and Cornell (2000) are developed using the software DRAIN-2DX. The models implemented in this study are developed in OpenSees. The elements used in the DRAIN-2DX models correspond to concentrated plastic hinge models and a linear axial force-bending moment (P-M) interaction surface was assumed for compressive axial loads greater than $0.15 P_{y}$. Whereas the model in FEMA (2000a) considers this simplified bilinear P-M interaction surface, the P-M interaction surface considered in this study is obtained implicitly during the analysis because the columns are modeled by using fiber section nonlinear beam-column elements. A representation of the P-M interaction curve (at the section level) is presented in Fig. 2(d).

The model validation performed in this study includes the comparison of results for both a nonlinear static pushover and nonlinear dynamic time-history analysis. Furthermore, the buildings periods available in the literature also correlate well with those obtained in the finite-element models developed in this work, as shown in Table 2.

The nonlinear static analyses are conducted by considering the four models described in Table 1 . The results obtained from these analyses are compared to those presented by FEMA (2000a) and Luco (2002). The applied lateral load pattern is proportional to the first mode of vibration of each structure.

Figs. 4, 5, and 6 show the pushover curves for each of the three buildings and the four finite-element models in use. For reference,

Table 2. Periods of Vibration for OpenSees and FEMA 355C Models

\begin{tabular}{|c|c|c|c|c|c|c|}
\hline \multirow[b]{2}{*}{$\begin{array}{l}\text { Modes of } \\
\text { vibration }\end{array}$} & \multicolumn{2}{|c|}{ LA3 } & \multicolumn{2}{|c|}{ LA9 } & \multicolumn{2}{|c|}{ LA20 } \\
\hline & OpenSees & $\begin{array}{c}\text { FEMA } \\
355 \mathrm{C} \\
(2000 \mathrm{a})\end{array}$ & OpenSees & $\begin{array}{c}\text { FEMA } \\
355 \mathrm{C} \\
(2000 \mathrm{a})\end{array}$ & OpenSees & $\begin{array}{c}\text { FEMA } \\
355 \mathrm{C} \\
(2000 \mathrm{a})\end{array}$ \\
\hline First mode (s) & 1.04 & 1.03 & 2.40 & 2.34 & 4.10 & 3.98 \\
\hline Second mode (s) & 0.34 & 0.33 & 0.90 & 0.88 & 1.40 & 1.36 \\
\hline Third mode (s) & 0.18 & 0.17 & 0.52 & 0.50 & 0.81 & 0.79 \\
\hline
\end{tabular}




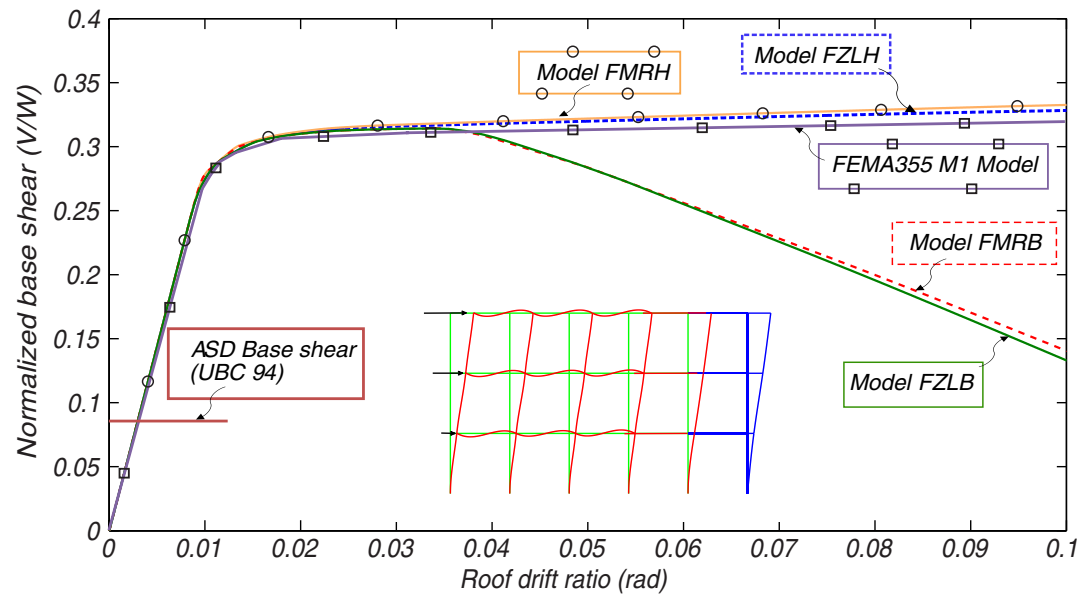

Fig. 4. LA3 building: nonlinear static (pushover) capacity curve considering a first mode lateral load pattern

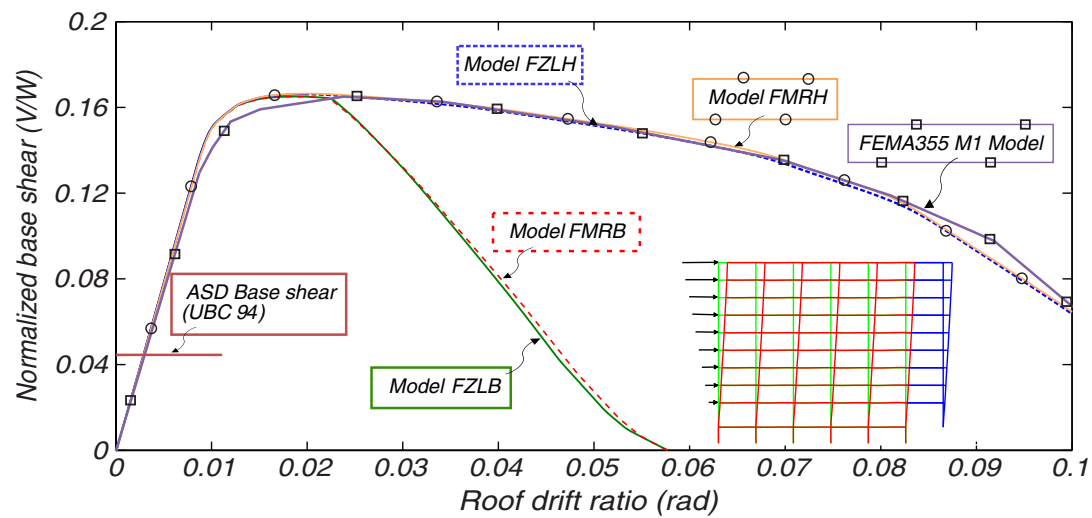

Fig. 5. LA9 building: nonlinear static (pushover) capacity curve considering a first mode lateral load pattern

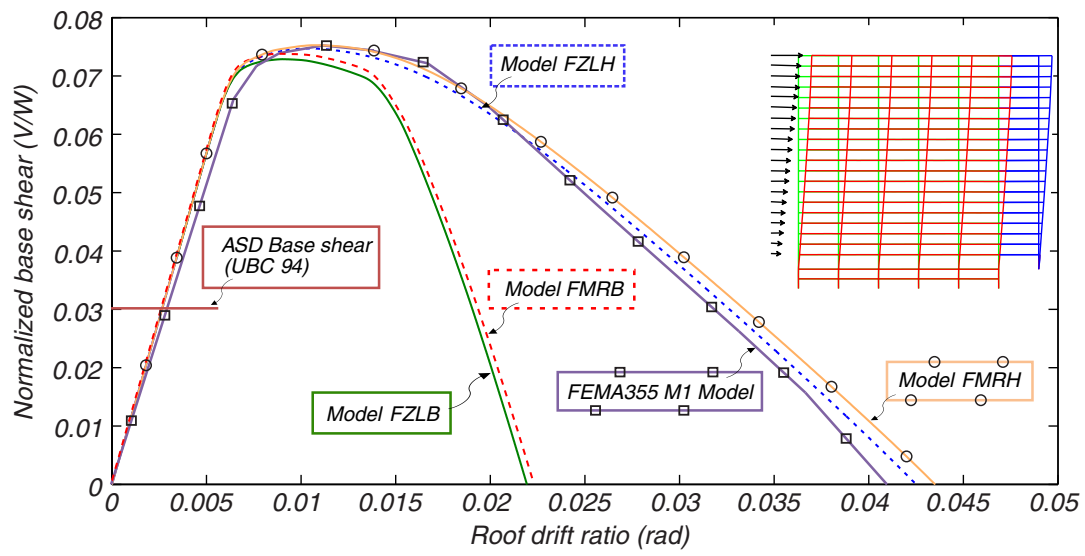

Fig. 6. LA20 building: nonlinear static (pushover) capacity curve considering a first mode lateral load pattern

these figures also show the design base shear, quantified according to the allowable stress design method (ASD) of the 1994 Uniform Building Code (ICBO 1994). These figures show that the overall matches of the pushover curve are quite good for the models with hardening. In the elastic range, the differences for all models to the results presented in FEMA (2000a) are small, increasing slightly with the increase in building height. Although the differences for the 20-story building are discernible in the elastic range, as shown in FEMA 355C (2000a), such variations are expectable as a consequence, for example, of alternative beam-column joint modeling. For all buildings, the models considering an elastoplastic with hardening constitutive law (FMRH, FZLH, and FEMA 355) present similar behavior, showing that the use of models of beams with hinges does not significantly affect the results. For the two taller buildings, a softening behavior is observable in all models as a result of $P-\Delta$ effects. When the bilinear model with 
deterioration is considered (FMRB and FZLB), the postpeak force decreases faster as a result of the strength deterioration considered for the beams. As a consequence of the strong column, weak beam design, plastic hinges form first in the beams. The use of the bilinear model with deterioration (FMRB and FZLB) leads to a faster decrease in the postpeak base shear force as a result of softening in the beams and a corresponding change in column moment gradient once the plastic hinges form.

In summary, the results of the pushover analysis show that the models using an elastic-plastic constitutive law lead to results similar to those described in FEMA 355C (2000a). Second, the use of zero length and beams with hinges does not significantly affect the results, allowing the use of the finite-length plastic hinges model in subsequent analyses. Finally, the use of the bilinear model with deterioration for the beams produced a larger strength reduction.

To compare the results described by Luco and Cornell (2000) with those resulting from the models used in this work, the structural response is evaluated considering 40 (20 two-component records) SAC Steel Project LA01-LA40 earthquake records (Somerville et al. 1997). Forty nonlinear dynamic time-history response analyses are performed for each model and each of the three buildings. The results were compared to those presented by Luco and Cornell (2000) in terms of maximum interstory drift ratio. The mean relative errors obtained for each model and building are presented in Table 3. For the models considering an elastic-plastic behavior (FZLH and FMRH), the results are relatively close, with a maximum mean error of $7.4 \%$. Correlation is also quite good between the floor levels in which these interstory drift ratios are observed for the models developed by Luco and Cornell (2000). Further details on the correlation study between the different models are provided in Ribeiro et al. (2012).

The model validation is considered to be sufficient for the FZLH and FMRH models. Although no direct validation of the FZLB and FMRB models with experimental results is possible, the definition of component degradation is consistent with experimental results and P-M interaction is explicitly considered. Considering the advantages of the described finite length model and including realistic effects of the deterioration of beam properties in the analysis, the FMRB model is used in the subsequent analyses.

\section{Description of Analysis}

To evaluate the increased probability of failure associated with the occurrence of an aftershock following a major earthquake, a simulation procedure was employed, in which the spectral accelerations of the mainshock and the aftershock (at the initial fundamental period of the structure) were considered to be random variables. Although the occurrence rate and distribution of aftershocks are correlated to the magnitudes of mainshocks (Yeo and Cornell 2005), their amplitude, frequency content, and duration are very difficult to simulate. Thus, artificial mainshock-aftershock sequences are used herein, following Luco et al. (2011), Ryu et al. (2011), and Li et al. (2012).

Table 3. Mean Relative Differences in Peak IDR to Model M1

\begin{tabular}{lcccc}
\hline & \multicolumn{4}{c}{ Model } \\
\cline { 2 - 5 } Building & FZLH $(\%)$ & FMRH $(\%)$ & FMRB (\%) & FZLB (\%) \\
\hline LA3 & 4.6 & 4.0 & 5.6 & 8.7 \\
LA9 & 4.5 & 5.1 & 6.4 & 8.4 \\
LA20 & 7.4 & 6.3 & 9.3 & 9.8 \\
\hline
\end{tabular}

Note: Model M1 is described in FEMA 355C (2000a).

\section{Numerical and Computational Methods}

The mainshock and aftershock are modeled by considering a set of 10 accelerograms, each scaled independently, representing different shaking intensities. For performing the IDA, each of the 10 mainshocks under consideration is scaled 10 times by multiplying the correspondent time-history record by the objective spectral acceleration, $S^{m}\left(T_{1}\right)$, divided by the original ground motion spectral acceleration, $S^{G M}\left(T_{1}\right)$, corresponding to a stratified sampling of the spectral accelerations. Each of the mainshocks can be followed by one of the 10 aftershocks. For each aftershock, an IDA is also performed for at least 20 intensity levels. Thus, in this analysis, the aftershock ground motion is incrementally scaled [by multiplying the time-history record by $\left.S^{a}\left(T_{1}\right) / S^{G M}\left(T_{1}\right)\right]$, similarly to the procedure of a regular IDA, performing $n$ back-to-back analyses, where $n$ depends on the aftershock ground motion, the building under analysis, and the damage state at the end of the mainshock. Each aftershock incremental dynamic analysis (AIDA) is computed considering the polarity of the aftershock (positive and negative directions). A $30 \mathrm{~s}$ time interval of free vibration is considered between the end of the mainshock and the application of the aftershock ground motion records. This duration was deemed to be sufficient after a preliminary study that showed that the maximum nodal velocity observed during the last second of this $30 \mathrm{~s}$ interval was, for all buildings, smaller than $0.6 \%$ of the peak velocity observed for the mainshock, leading to the highest drifts short of collapse.

For each run, the Newton-Raphson method is used to solve the nonlinear system of equations at each time step. To analyze the structure up to interstory drift ratios of $10 \%$, a convergence study is performed of the horizontal roof peak displacement and horizontal peak floor absolute acceleration as a function of the integration time step. Time steps under consideration are 0.01, 0.005, $0.002,0.001,0.0005,0.0001$, and $0.00005 \mathrm{~s}$. A time step of $0.002 \mathrm{~s}$ is sufficiently small to produce negligible errors (when compared to $0.00005 \mathrm{~s}$ ) and no significant changes in the response are observed when smaller time steps are used.

To reduce the total computational time required to obtain all of the results for these larges number of runs, an embarrassingly parallel computing framework is implemented. The implemented framework makes use of the OpenSees (version 2.4.0, release 5172) sequential version and a batch queue system called HTCondor (version 7.8.0) (Thain et al. 2005). HTCondor is a specialized batch system for managing computationally intensive jobs. To make the most use of two student computer centers of Civil Engineering Departments at both Oregon State University (OSU) and Universidade Nova de Lisboa (UNL), two HTCondor pools were created, consisting of 464 cores at OSU and 96 cores at UNL. Because the research team was geographically dispersed, to minimize time needed for simulation data transfer and postprocessing of the numerical results, an OSU-UNL shared web folder was created by using a commercial application.

\section{Ground Motion Records}

The ground motion records used in this study were selected from the set of 40 SAC Steel Project LA01-LA40 earthquake records mentioned previously, considering earthquakes with the highest peak ground acceleration. These records were obtained from real and simulated ground motions, scaled so that their mean response spectra matched the 1997 National Earthquake Hazards Reduction Program (NEHRP) design spectrum, as reported by Somerville et al. (1997). The time histories for Los Angeles are all derived from recordings of shallow crustal earthquakes on Soil Category D. The 10 SAC records selected for this study are characterized by a moment magnitude $M_{W}$ between 6.0 and 7.4 , duration 
between 29.9 and 59.9 s, and peak ground acceleration between 0.6 and $1.3 \mathrm{~g}$. The $10 \mathrm{E} 1$ to E10 ground motion records in use correspond to SAC earthquakes: LA11, LA18, LA19, LA21, LA26, LA28, LA30, LA31, LA36, and LA37.

To quantify the probability of failure of the structures, the spectral accelerations at Los Angeles are estimated from the hazard curves generated for the 2008 National Seismic Hazard Mapping Project (NSHMP) (Petersen et al. 2008) for Soil Type D. These are approximated by a lognormal distribution, under the mild assumption that the findings of Jayaram and Baker (2008) also hold for the modified ground motion records.

\section{Deterministic Nonlinear Dynamic Time-History Response Analysis}

This section presents results obtained for representative nonlinear dynamic time-history response analyses, selected from those described previously. The performance of the LA3 building is assessed, considering a mainshock ground motion spectral acceleration of $1.2 \mathrm{~g}$ and aftershock spectral acceleration of $0.9 \mathrm{~g}$. Earthquake ground motions E1 and E4 are used as the mainshock and aftershock, respectively.

Fig. 7 shows the time-history response of the LA3 building in terms of floor acceleration, roof drift ratio (RDR), and interstory drift ratio (IDR) during four identified time periods (TP1-TP4): (1) TP1 is the duration of the mainshock; (2) TP2 is the free vibration period of $30 \mathrm{~s}$ after the mainshock; (3) TP3 is the duration of the aftershock; and (4) TP4 is the free vibration period of $30 \mathrm{~s}$ after the aftershock. This figure also shows the floor accelerations and the interstory drift ratios at the instants when peak interstory drift ratio is attained during the mainshock and the aftershock, respectively. The peak interstory drift ratio during the mainshock is $4.1 \%$ at the third story. In Fig. 8 two moment-rotation responses are shown at two different elements. During the aftershock, the deformations are much larger, for responses that go beyond the peak strength. This is notable in the in the moment-rotation response of the beam [Fig. 8(b)], which exhibits softening response for rotations greater that $0.03 \mathrm{rad}$.

The deformed shape of the LA3 building at the instant of peak deformation is shown in Fig. 9. This figure also shows the deformed shapes of LA9 and LA20, in which, for representative analyses, the sizes of the circles illustrate the relative scales of rotations recorded at the end of each element. For LA3, almost all beam ends go into the inelastic regime during the mainshock. Although the damage on the structure at the end of the mainshock is considerable, as can be inferred through the number of plastic hinges formed during the mainshock, the residual deformation is not significant (Fig. 7). At the instant when the peak interstory drift ratio is recorded during the aftershock, columns on the first story have formed plastic hinges in both ends, which indicates that an undesirable soft story mechanism is formed. Four plastic hinges have also formed in second story columns and two in the third. The effects of higher modes in the instants when peak interstory drifts are recorded can be observed in the responses of LA9 and LA20, especially during the aftershock (Fig. 9).

\section{Aftershock Incremental Dynamic Analysis}

For each combination of mainshock and aftershock and each intensity of the mainshock, an AIDA for increasing aftershock

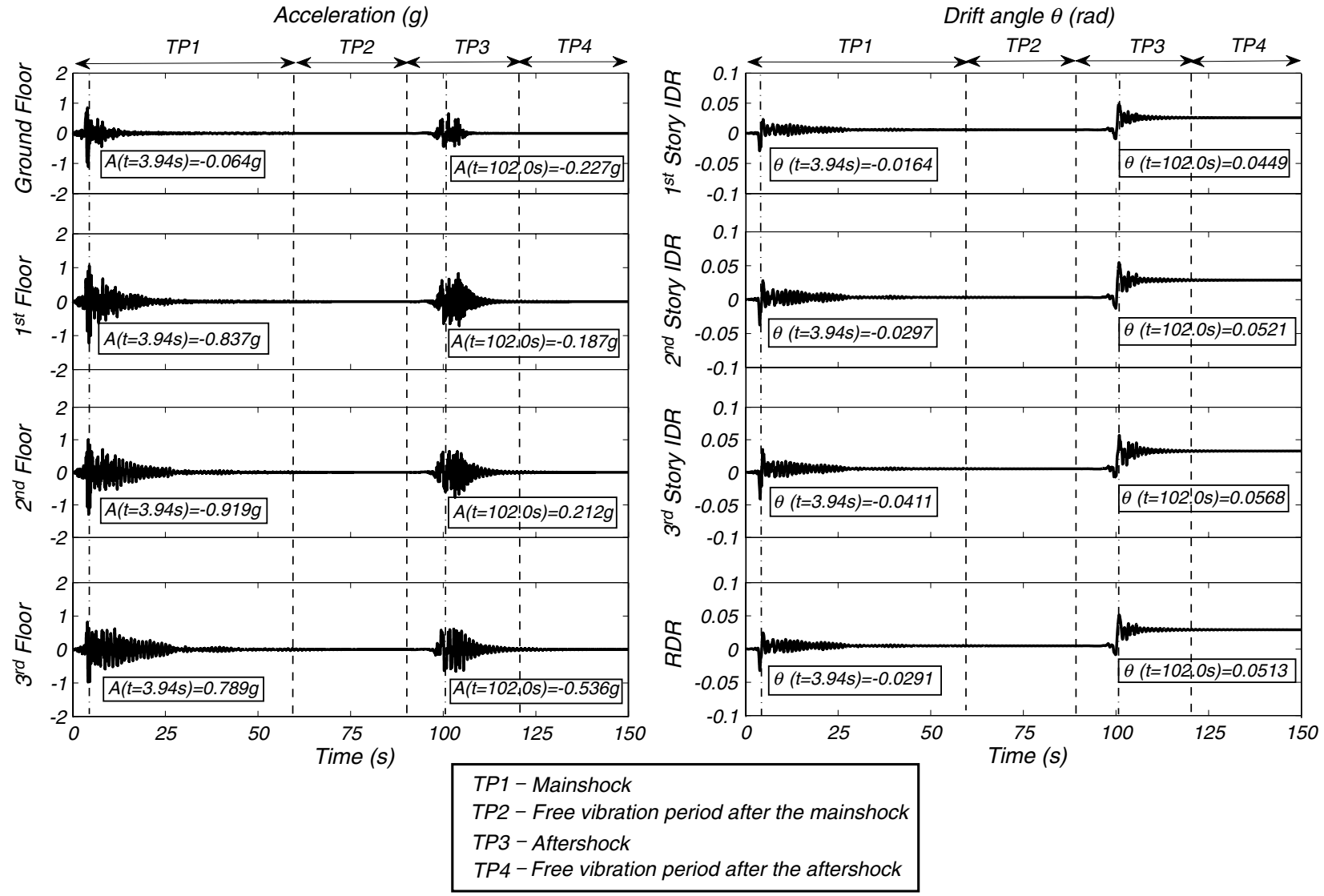

Fig. 7. LA3 building: example mainshock-aftershock back-to-back time-history responses for floor absolute acceleration, interstory drift ratio (IDR), and roof drift ratio (RDR) 

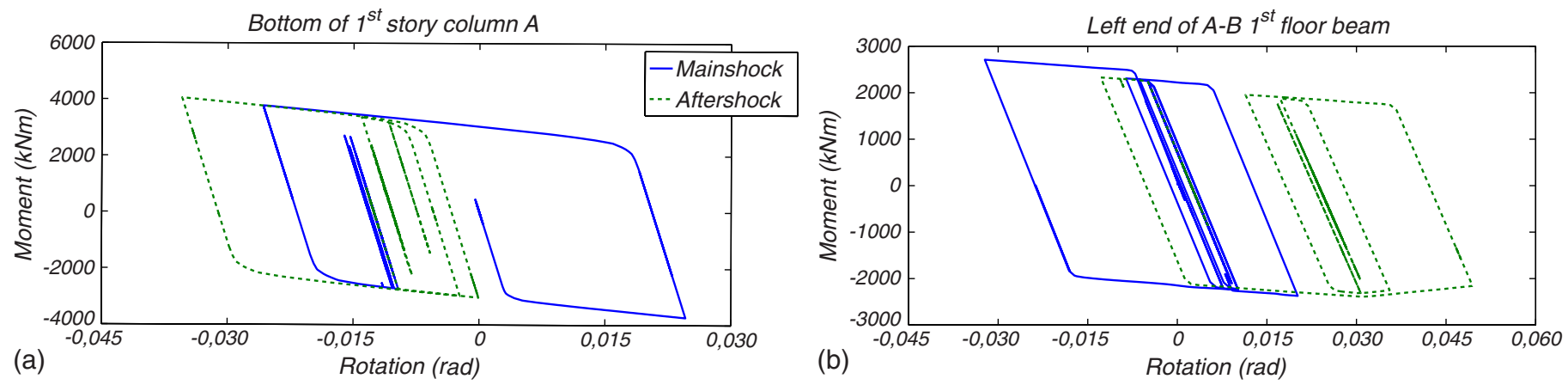

Fig. 8. LA3 building hinge moment-rotation response at: (a) bottom of first story in Grid Line A; (b) left end of first floor level Beam A-B

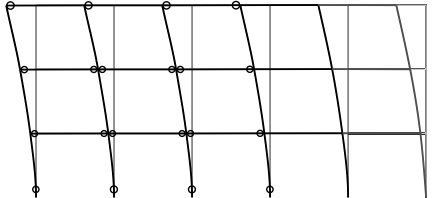

(a)

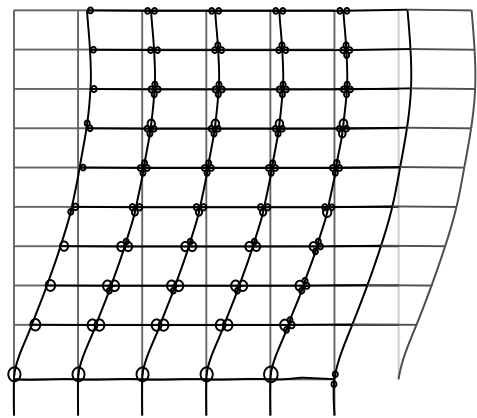

(c)

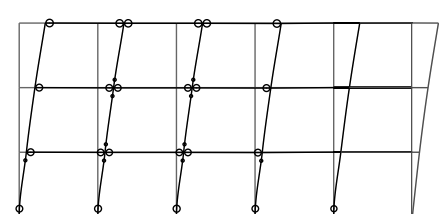

(b)

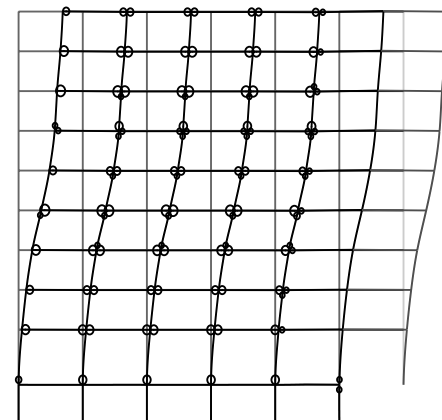

(d)

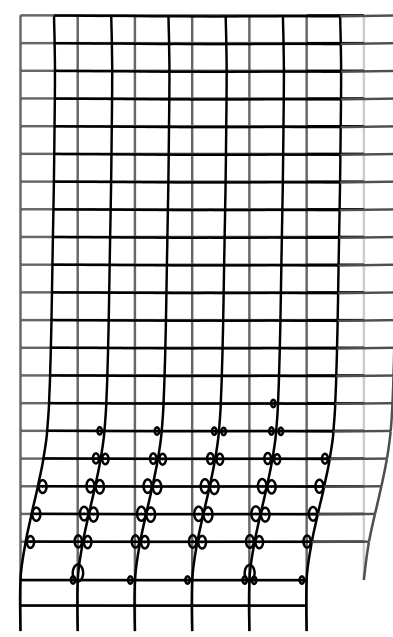

(e)

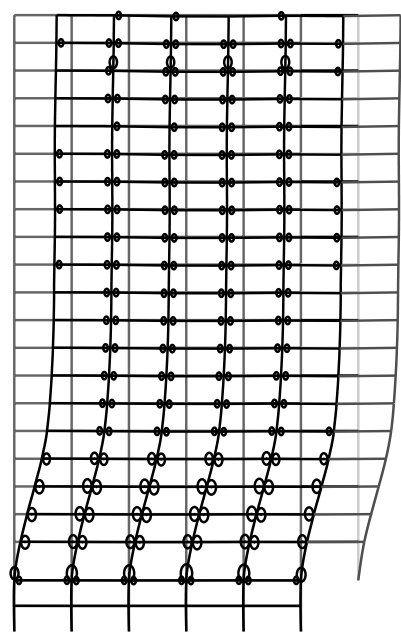

(f)

Fig. 9. Deformed shapes of the buildings at two different instants: (a) peak interstory drift ratio during the mainshock for LA3; (b) peak interstory drift ratio during the aftershock for LA3 (c) peak interstory drift ratio during the mainshock for LA9; (d) peak interstory drift ratio during the aftershock for LA9; (e) peak interstory drift ratio during the mainshock for LA20; (f) peak interstory drift ratio during the aftershock for LA20
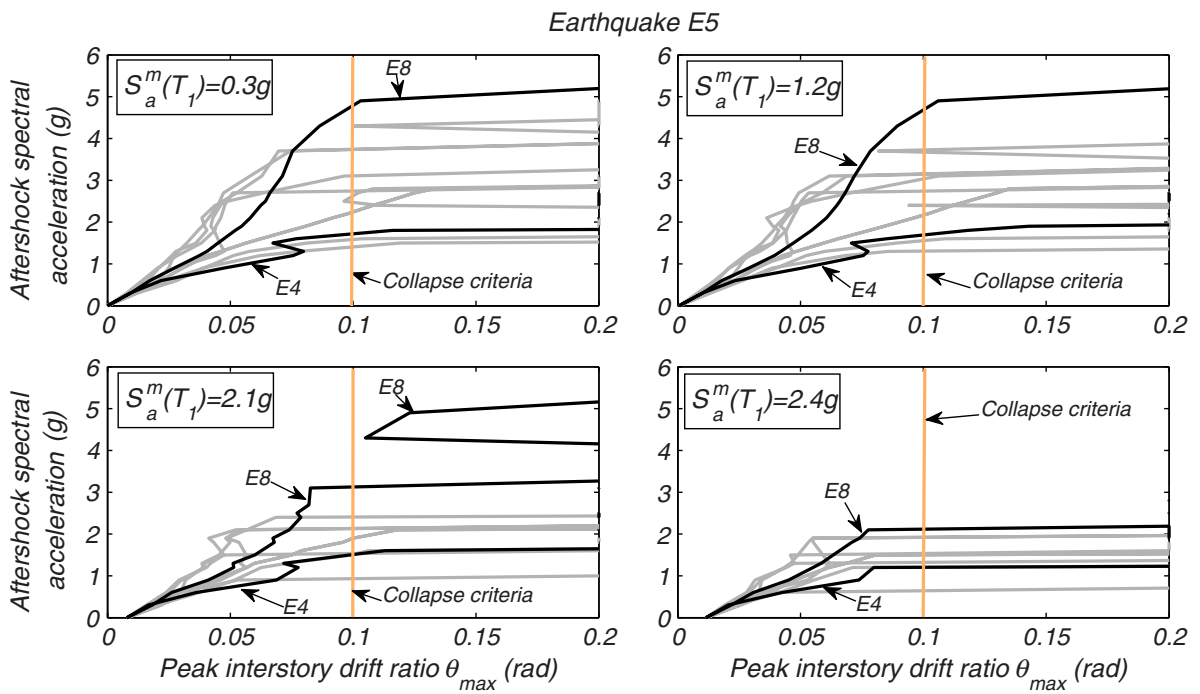

Fig. 10. LA3 building: aftershock IDA curves for 10 earthquake records and four different mainshock ground motion spectral accelerations 
intensities is performed to compute the failure probability under this sequence of events. In Fig. 10, AIDA curves are shown for four mainshock ground motion spectral accelerations. For the sake of brevity, only results from the LA3 building are shown. Earthquake E5 is considered to be the mainshock. Ten AIDA curves are computed for the 10 possible aftershocks. For each mainshock intensity, the results show the variation of the peak interstory drift ratio, $\theta_{\max }$, as a function of the ground motion spectral acceleration of the aftershock.

The value of $10 \%$ of interstory drift ratio is considered to be the threshold for failure (Baker 2007). Higher values of IDR will lead to violation of the performance threshold, and thus, be considered as failure. Previous probability based studies (Baker 2007) have concluded that $10 \%$ IDR is an adequate threshold to define collapse in a numerical framework. Although FEMA 356 (2000b) defines 5\% IDR for collapse prevention, to study the structural robustness (i.e., the capacity of the structure to sustain damage), this larger value allows for the assessment of the nonlinear structural behavior under very large deformations, which contributes to the accurate evaluation of the reliability based structural robustness by allowing for more accurate computation of the probability of failure.

Fig. 10 shows the AIDA curves illustrating the decrease in capacity with the increase in mainshock intensity. For example, the ground motion spectral acceleration of Aftershock E4 that leads the structure to failure is $1.7 \mathrm{~g}$ when the ground motion spectral acceleration of the mainshock is $1.2 \mathrm{~g}$, whereas when the ground motion spectral acceleration of the mainshock is $2.4 \mathrm{~g}$, the spectral acceleration of the aftershock that leads to failure is $1.1 \mathrm{~g}$.

\section{Results of Robustness Assessment}

Fig. 11 shows the lowest spectral acceleration of the aftershock that leads the LA3 building to fail $\left(\theta_{\max }=10 \%\right)$ versus the spectral acceleration of the mainshock. The figure corresponds to results obtained by using Earthquake E5 for both the mainshock and the aftershock. The figure shows that for lower intensities of the mainshock, there is little impact of mainshock on the spectral acceleration of the aftershock that leads to failure. Additionally, for increasing mainshock intensities, the spectral accelerations of the aftershock that lead to failure are reduced, because the mainshock induced damage reduces the capacity of the structure to sustain additional damage as a result of the aftershocks. Because the same accelerograms are used for generating both mainshock and

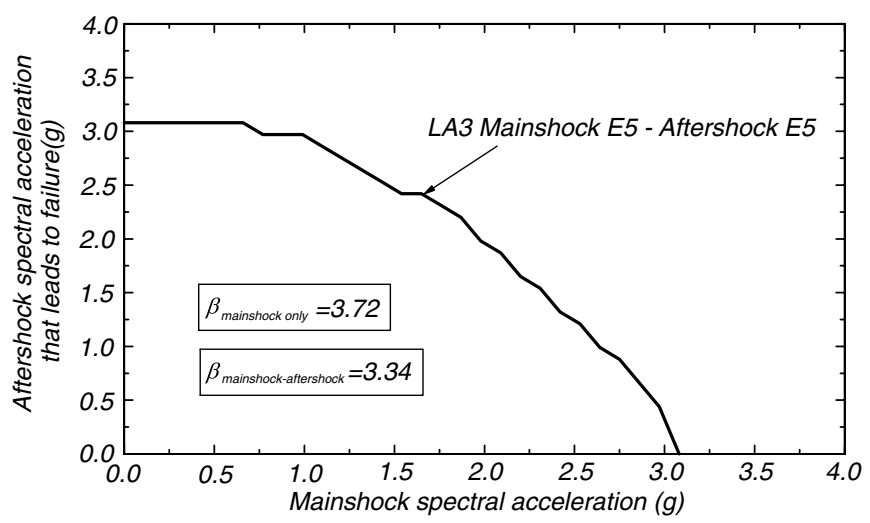

Fig. 11. LA3 building: aftershock ground motion spectral acceleration at the fundamental period of the intact structure that leads to failure as a function of the mainshock ground motion spectral acceleration for Earthquake E5 aftershock, the applications of a mainshock only or an aftershock following a low intensity mainshock (i.e., causing no damage to the structure) are equivalent. Consequently, the lowest mainshock spectral acceleration leading to failure is identical to the (minimum) aftershock spectral acceleration, which leads to failure for very low mainshock intensities.

In Fig. 12, the median ground motion spectral acceleration of the aftershock that leads the structures to failure is represented as a function of the median ground motion spectral acceleration of the mainshock. A similar trend to that shown in Fig. 11 is observable here, but for the entire set of AIDA analyses under consideration. Fig. 12 also shows the median residual displacements after application of the mainshock. The results show a significant correlation between the increase in residual displacements and the reduction in the aftershock leading to failure, indicating that residual displacements can be used as a measure of damage.

In Table 4, the probabilities of failure and the corresponding reliability indices are presented, considering mainshock, aftershock, and mainshock plus aftershock. The redundancy indicator, $\beta_{r}$, introduced by Frangopol and Curley (1987), is used to compare the robustness of the three buildings. The reliability indexes obtained by considering only the mainshock are very similar across structures, showing that the applied design procedure is consistent. However, the probability of failure considering aftershock and mainshock-induced damage increases much more significantly for Buildings LA3 and LA20 than for LA9.

The results obtained for the redundancy index, $\beta_{r}$, show that LA9, although less safe than LA3 and LA20 under a mainshock

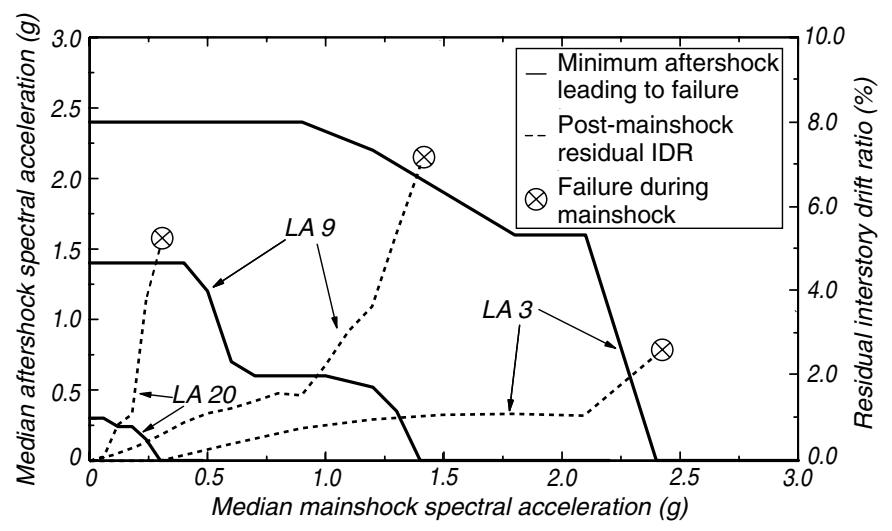

Fig. 12. Median lowest aftershock ground motion spectral acceleration at the fundamental period of the intact structure that leads to failure (solid line and left vertical axis) and median residual IDR after mainshock (dashed line and right vertical axis) as a function of the median ground motion spectral acceleration of the mainshock

Table 4. Probabilities of Failure, Reliability Indexes, and Redundancy Index Associated with the Scenarios

\begin{tabular}{lccc}
\hline Scenario & LA3 & LA9 & LA20 \\
\hline Mainshock & & & \\
$\quad$ Probability of failure $\left(p_{f 1}\right)$ & $3.56 \times 10^{-4}$ & $7.22 \times 10^{-4}$ & $6.17 \times 10^{-4}$ \\
Reliability index $(\beta)$ & 3.38 & 3.19 & 3.23 \\
Mainshock U aftershock & & & \\
$\quad$ Probability of failure $\left(p_{f 3}\right)$ & $1.02 \times 10^{-3}$ & $1.66 \times 10^{-3}$ & $2.23 \times 10^{-3}$ \\
$\quad$ Reliability index $(\beta)$ & 3.08 & 2.94 & 2.84 \\
Aftershock | mainshock & & & \\
$\quad$ Probability of failure $\left(p_{f 2}\right)$ & $6.64 \times 10^{-4}$ & $9.39 \times 10^{-4}$ & $1.61 \times 10^{-3}$ \\
$\quad$ Reliability index $(\beta)$ & 3.21 & 3.11 & 2.95 \\
Redundancy index, $\beta_{r}$ & 19.32 & 41.52 & 11.31 \\
\hline
\end{tabular}


alone, is significantly more robust. These results can be correlated to the ability of LA9 to distribute damage over the entire height of the building, as shown in Fig. 9.

\section{Conclusions}

In this paper, a reliability based robustness assessment methodology for SMRF structures subjected to post-mainshock seismic events is proposed and exemplified. Robustness is computed through comparison of the structural reliability index under a mainshock, considering the undamaged structure, and under an aftershock applied to the mainshock-damaged structure. Probabilities of failure are computed through simulation, using nonlinear finite-element models that explicitly reproduce damage induced by strong shaking. The methodology is exemplified by using back-to-back mainshock-aftershock nonlinear dynamic time-history analyses.

For structures expected to form strong column, weak beam failure mechanisms, a finite-element modeling approach is presented, in which columns are modeled by using force-based fiber section distributed plasticity elements and beams are modeled by using a recently proposed phenomenological bilinear model with deterioration. The models used for the columns directly account for axial load bending moment interaction. For the beams, the deterioration behavior defined for the plastic hinges is fundamental for accurate performance assessments under mainshock-aftershock sequences. The finite-length plastic hinge element is used because of its ability to explicitly model plastic hinge lengths and to separate the behavior of the beam in the span from that of beam-column connections.

Two-dimensional models of three, nine, and 20-story steel buildings, designed for the SAC project for Los Angeles, California, are implemented in the OpenSees framework. To simulate the mainshock-aftershock sequence of events, 10 different mainshock and aftershock ground motion records are combined. The spectral accelerations at fundamental periods of the buildings are used to simulate mainshock and aftershock intensities that follow lognormal distributions. Back-to-back mainshock-aftershock IDAs are performed for each combination of mainshock and aftershock, and failure is defined in terms of the exceedance of an interstory drift threshold. The results presented here are sensitive to the frequency content of the ground motions (both aftershock and mainshock), period elongation attributable to cyclic deterioration in stiffness from the mainshock, and the definition of the fundamental period of the frame structures. These important factors are not considered herein, and as discussed by Faggella et al. (2013), can only be adequately accounted for by using a vector-valued ground motion intensity measure. The use of vector-valued ground motion intensity measures falls outside the scope of this paper.

Application of the reliability based robustness assessment shows the importance of considering the aftershock in the evaluation of safety of structures under seismic events, because a significant increase in failure probability is observed when mainshock-aftershock sequences are considered. Moreover, this study shows that the LA9 building, although initially more susceptible to failure than LA3 and LA20, presents significantly higher robustness for the aftershock events $\left(\beta_{r}=41.52\right.$ for LA9 versus $\beta_{r}=$ 19.32 and $\beta_{r}=11.31$ for LA3 and LA20, respectively). In fact, robustness is defined in terms of the increase in probability of failure considering damage, and LA9, although less safe than LA3 and LA20 under a mainshock alone, presents a lower reduction in reliability index when cascading events are considered. Thus, it can also be concluded that the probabilities of failure for multiple hazards require explicit modeling of the hazards and simulation methods need to accurately model the damage induced by the cascading hazards.

\section{Acknowledgments}

In the development of this research work, the first and third author would like to acknowledge the support of the Portuguese Science and Technology Foundation through the fellowship SFRH/BD/ 77722/2011 and UNIC Research Center at the New University of Lisbon. The support of the School of Civil and Construction Engineering at Oregon State University to the second author is gratefully acknowledged. The second author would also like to thank Dr. Nicolas Luco (USGS) for the fruitful discussions on the validation of the finite element models. The first author would also like to acknowledge the support of Oregon State University during the period in which he was a visiting Ph.D. student. The support of the Nottingham Transportation Engineering Center to the third author is gratefully acknowledged. The opinions and conclusions presented in this paper are those of the authors and do not necessarily reflect the views of the sponsoring organizations.

\section{References}

Baker, J., Schubert, M., and Faber, M. (2008). "On the assessment of robustness." Struct. Saf., 30(3), 253-267.

Baker, J. W. (2007). "Probabilistic structural response assessment using vector-valued intensity measures." Earthquake Eng. Struct. Dyn., 36(13), 253-267.

Bommer, J. J., and Acevedo, A. B. (2004). "The use of real earthquake accelerograms as input to dynamic analysis." J. Earthquake Eng., 8(1), 43-91.

Cavaco, E., Casas, J., Neves, L., and Huespe, A. (2013). "Robustness of corroded reinforced concrete structures: A structural performance approach." Struct. Infrastruct. Eng., 9(1), 42-58.

Coleman, J., and Spacone, E. (2001). "Localization issues in force-based frame elements." J. Struct. Eng., 10.1061/(ASCE)0733-9445(2001) 127:11(1257), 1257-1265.

DRAIN-2DX [Computer software]. Univ. of California, Berkeley, CA.

Erduran, E. (2012). "Evaluation of Rayleigh damping and its influence on engineering demand parameter estimates." Earthquake Eng. Struct. Dyn., 41(14), 1905-1919.

Faggella, M., Barbosa, A. R., Conte, J. P., Spacone, E., and Restrepo, J. I. (2013). "Probabilistic seismic response analysis of a 3-D reinforced concrete building." Struct. Saf., 44, 11-27.

FEMA. (2000a). "State of the art report on systems performance of steel moment frames subjected to earthquake ground shaking." FEMA-355C, Washington, DC.

FEMA. (2000b). "Prestandard and commentary for the seismic rehabilitation of buildings." FEMA-356, Washington, DC.

Fragiacomo, M., Amadio, C., and Macorini, L. (2004). "Seismic response of steel frames under repeated earthquake." Eng. Struct., 26(13), 2021-2035.

Frangopol, D., and Curley, J. (1987). "Effects of damage and redundancy on structural reliability." J. Struct. Eng., 10.1061/(ASCE)0733-9445 (1987)113:7(1533), 1533-1549.

Giberson, M. (1969). "Two nonlinear beams with definitions of ductility." J. Struct. Div., 95(2), 137-157.

Gupta, A., and Krawinkler, H. (1999). "Seismic demands for performance evaluation of steel moment resisting frame structures." Rep. No. 132, John A. Blume Earthquake Engineering Center, Stanford, CA.

Haselton, C., and Deierlein, G. (2007). "Assessing seismic collapse safety of modern reinforced concrete frame buildings." Rep. No. 156, John A. Blume Earthquake Engineering Center, Stanford, CA.

HTCondor, version 7.8.0 [Computer software]. Madison, WI, Univ. of Wisconsin.

Ibarra, L. F., and Krawinkler, H. (2005). "Global collapse of frame structures under seismic excitations." Rep. No. 152, John A. Blume 
Earthquake Engineering Research Center, Dept. of Civil Engineering, Stanford University, Stanford, CA.

International Conference of Building Officials (ICBO). (1994). "Structural engineering design provisions." Uniform building code, Vol. 2, Whittier, CA.

Jayaram, N., and Baker, J. (2008). "Statistical tests of the joint distribution of spectral acceleration values." Bull. Seismol. Soc. Am., 98(5), 2231-2243.

Kiureghian, A. D. (1996). "Structural reliability methods for seismic safety assessment: A review." Eng. Struct., 18(6), 412-424.

Lee, K., and Foutch, D. (2004). "Performance evaluation of damaged steel frame buildings subjected to seismic loads." J. Struct. Eng., 10.1061/ (ASCE)0733-9445(2004)130:4(588), 588-599.

Li, Q., and Ellingwood, B. R. (2007). "Performance evaluation and damage assessment of steel frame buildings under main shock-aftershock earthquake sequences." Earthquake Eng. Struct. Dyn., 36(3), 405-427.

Li, Y., Song, R., van de Lindt, J., Nazari, N., and Luco, N. (2012). "Assessment of wood and steel structures subjected to earthquake mainshockaftershock." 15th World Conf. on Earthquake Engineering, Lisbon, Portugal.

Lignos, D., and Krawinkler, H. (2012). "Development and utilization of structural component databases for performance-based earthquake engineering." J. Struct. Eng., 10.1061/(ASCE)ST.1943-541X.0000646, 1382-1394.

Lignos, D. G., Chung, Y., Nagae, T., and Nakashima, M. (2011). "Numerical and experimental evaluation of seismic capacity of high-rise steel buildings subjected to long duration earthquakes." Comput. Struct., 89(11-12), 959-967.

Lignos, D. G., and Krawinkler, H. (2011). "Deterioration modeling of steel components in support of collapse prediction of steel moment frames under earthquake loading." J. Struct. Eng., 10.1061/(ASCE)ST.1943541X.0000376, 1291-1302.

Lind, N. C. (1995). "A measure of vulnerability and damage tolerance." Reliab. Eng. Syst. Saf., 48(1), 1-6.

Luco, N. (2002). "Probabilistic seismic demand analysis, SMRF connection fractures, and near-source effects." Ph.D. thesis, Dept. of Civil and Environmental Engineering, Stanford University, Stanford, CA.

Luco, N., Bazzurro, P., and Cornell, C. A. (2004). "Dynamic versus static computation of the residual capacity of a mainshock-damaged building to withstand an aftershock." Proc., of the 13th World Conf. on Earthquake Engineering, Vancouver, Paper No. 2405.

Luco, N., and Cornell, C. A. (2000). "Effects of connection fractures on SMRF seismic drift demands." J. Struct. Eng., 10.1061/(ASCE) 0733-9445(2000)126:1(127), 127-136.

Luco, N., Gerstenberger, M. C., Uma, S. R., Ryu, H., Liel, A. B., and Raghunandan, M. (2011). "A methodology for post-mainshock probabilistic assessment of building collapse risk." Proc., of the 9th Pacific Conf. on Earthquake Engineering, Auckland, New Zealand, Paper No. 210.
Medina, R., and Krawinkler, H. (2005). "Evaluation of drift demands for the seismic performance assessment of frames." J. Struct. Eng., 10.1061/(ASCE)0733-9445(2005)131:7(1003), 1003-1013.

Newell, J. D., and Uang, C.-M. (2008). "Cyclic behavior of steel wideflange columns subjected to large drift." J. Struct. Eng., 10.1061/ (ASCE)0733-9445(2008)134:8(1334), 1334-1342.

Newmark, N., and Rosenbleuth, E. (1971). Fundamental of earthquake engineering, Prentice-Hall, Englewood Cliffs, NJ.

OpenSees, Version 2.4.0 [Computer software]. Berkeley, CA, Pacific Earthquake Engineering Research Center.

Pacific Earthquake Engineering Research Center/Applied Techonology Council (PEER/ATC). (2010). "Modeling and acceptance criteria for seismic design and analysis of tall buildings." Rep. No. 72-1, Berkeley, CA.

Petersen, M., et al. (2008). "Documentation for the 2008 update of the United States national seismic hazard maps." U.S. Geological Survey Open-File Rep. 2008-1128, Reston, VA.

Ribeiro, F., Barbosa, A., and Neves, L. (2012). "Numerical analysis of steel moment resisting frames under mainshock-aftershock seismic sequences." Rep. No. Kiewit-2012/07, Oregon State University, Corvallis, OR.

Ruiz-García, J. (2012). "Mainshock-aftershock ground motion features and their influence in building's seismic response." J. Earthquake Eng., 16(5), 719-737.

Ryu, H., Luco, N., Uma, S. R., and Liel, A. (2011). "Developing fragilities for mainshock-damaged structures through incremental dynamic analysis." Proc., of the 9th Pacific Conf. on Earthquake Engineering, Auckland, New Zealand, Paper No. 225.

Scott, M., and Ryan, K. (2013). "Moment-rotation behavior of force-based plastic hinge elements." Earthquake Spectra, 29(2), 597-607.

Scott, M. H., and Fenves, G. L. (2006). "Plastic hinge integration methods for force-based beam-column elements." J. Struct. Eng., 10.1061/ (ASCE)0733-9445(2006)132:2(244), 244-252.

Somerville, P., Smith, N., Punyamurthula, S., and Sun, J. (1997). "Development of ground motion time histories for phase II of the FEMA/SAC steel project." Rep. No. SAC/BD-97/04, SAC Background Document, Richmond, CA.

Starossek, U. (2006). "Progressive collapse of structures: Nomenclature and procedures." Struct. Eng. Int., 16(2), 113-117.

Starossek, U., and Haberland, M. (2008). "Measures of structural robustness-Requirements and applications." ASCE SEI Structures Congress-Crossing Borders, ASCE, Reston, VA.

Thain, D., Tannenbaum, T., and Livny, M. (2005). "Distributed computing in practice: The condor experience." Concurrency, 17(2-4), 323-356.

Vamvatsikos, D., and Cornell, C. (2002). "Incremental dynamic analysis." Earthquake Eng. Struct. Dyn., 31(3), 491-514.

Yeo, G. L., and Cornell, C. (2005). "Stochastic characterization and decision bases under time-dependent aftershock risk in performance-based earthquake engineering." PEER Rep. 2005/13, Pacific Earthquake Engineering Research Center, College of Engineering, Berkeley, CA. 